\title{
The use of two-dimensional NMR spectroscopy to determine the rates of and activation parameters for the 3,2-hydride shift in the 2-norboryn cation
}

\author{
Kenneth Smith, ${ }^{1}$ Hongjun Pan, ${ }^{1}$ George Hondrogiannis, ${ }^{1}$ \\ Andrew Mamantov, ${ }^{2}$ and Richard M. Pagni ${ }^{*}$ \\ ${ }^{1}$ Department of Chemistry, University of Tennessee, Knoxville, TN 37996 \\ ${ }^{2}$ Environmental Protection Agency, Washington, D.C. 20460 \\ Email: rpagni@utk.edu
}

\section{Dedicated to Professor Ted Sorensen on the occasion of his retirement}

\begin{abstract}
Quantitative two-dimensional exchange spectroscopy has been used to determine the rates of and activation parameters for the 3,2-hydride shift in the 2-norbornyl cation. The results compare favorably with the published values obtained by line shape analysis.
\end{abstract}

Keywords: 2-Norbornyl cation, 3,2-hydride shift, EXSY, rates, activation parameters

\section{Introduction}

We recently published a paper describing the mechanism of the very unusual transformation of 2,2-dichloronorbornane into 1-chloronorbornane in a slurry of $\mathrm{AlCl}_{3} /$ pentane. ${ }^{1} \mathrm{~A}$ key intermediate in the rearrangement is the 2-chloro-2-norbornyl cation which was characterized using a number of one- and two-dimensional $\mathrm{nmr}$ spectroscopies. The 1-chloronorbornane generated in this reaction can be used to prepare the transitory 1-norbornyl cation which can be trapped in competition to its isomerization to the well-studied 2-norbornyl cation by an unknown mechanism. ${ }^{2}$

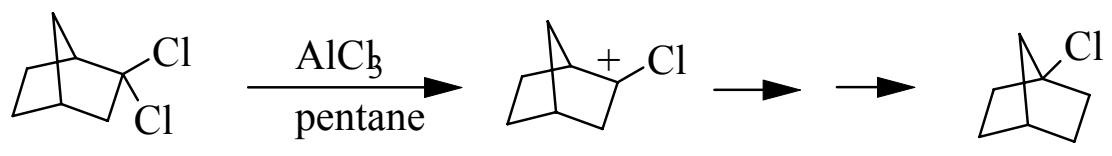

Although the 2-norbornyl cation has been well characterized by one-dimensional ${ }^{1} \mathrm{H}$ and ${ }^{13} \mathrm{C}$ $\mathrm{nmr}$ spectroscopy, it has not been, as far as we can tell, characterized by two-dimensional nmr 
spectroscopy. We now report such spectra. Of particular note is the quantitative exchange spectroscopy (EXSY) for the 3,2-hydride shift. We previously had used EXSY to demonstrate qualitatively that two Lewis acid-Lewis base complexes interconvert with one another. ${ }^{3}$ In this study the rates of the 3,2-hydride shift in the 2-norbornyl cation were determined and compared to the values obtained by line-shape analysis. ${ }^{4}$ Quantitative EXSY and line-shape analysis complement each other as they are applicable in different temperature regimes.
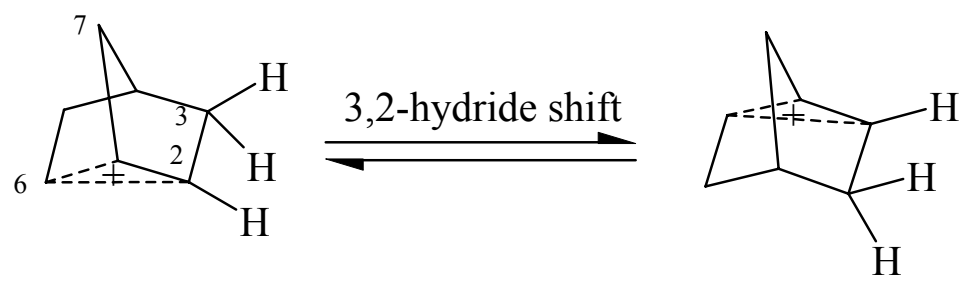

\section{Results and Discussion}

In Figure 1 is shown the COSY spectrum of the 2-norbornyl cation at $-80^{\circ} \mathrm{C}$. At the top $\mathrm{x}$ axis and at the $\mathrm{y}$ axis to the left of the COSY spectrum are shown the ${ }^{1} \mathrm{H}$ nmr spectrum of the ion which consists of three peaks at $\delta=1.85,2.82$, and $4.93 \mathrm{ppm}$ assigned to the six hydrogen atoms at positions 3,5 and 7, the unique $\mathrm{H}-4$, and the five hydrogen atoms at postions 1,2 and 6 . At $80^{\circ} \mathrm{C}$ the 3,2-hydride shift is slow but the 6.2-hydride shift is fast, yielding an ion with an apparent three-fold axis of symmetry. Three-bond coupling is apparent from the cross peaks connecting H-4 with the hydrogen atoms at positions 3, 5, and 7 and the hydrogen atoms at 3,5, and 7 with those of 1,2 , and 6 . There is no cross peak between the peak for H-4 and that due to hydrogen atoms 1,2 , and 6 , as expected 


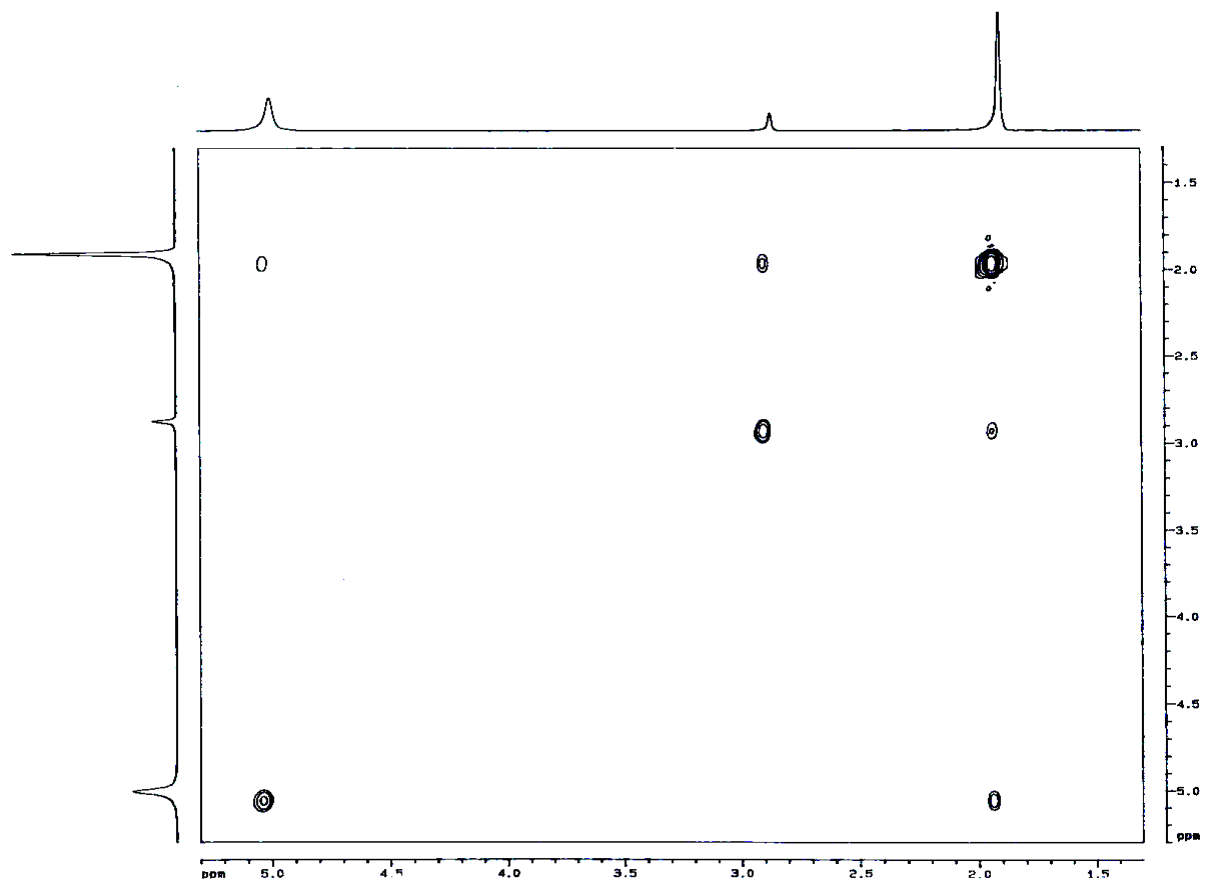

Figure 1. COSY spectrum of the 2-norbornyl cation at $193 \mathrm{~K}$.

In Figure 2 is shown the HMQC spectrum which correlates the hydrogen atoms of the ion to the carbon atoms to which they are attached. The ${ }^{13} \mathrm{C} \mathrm{nmr}$ spectrum (shown on the left y axis) shows three peaks at circa $\delta=35,45$ and 95 ppm due to carbons 3,5 and 7, the unique C-4, and carbon atoms 1,2, and 6. The peaks in the interior of the HMQC spectrum show that the hydrogen and carbon atoms correlate in the correct manner. 


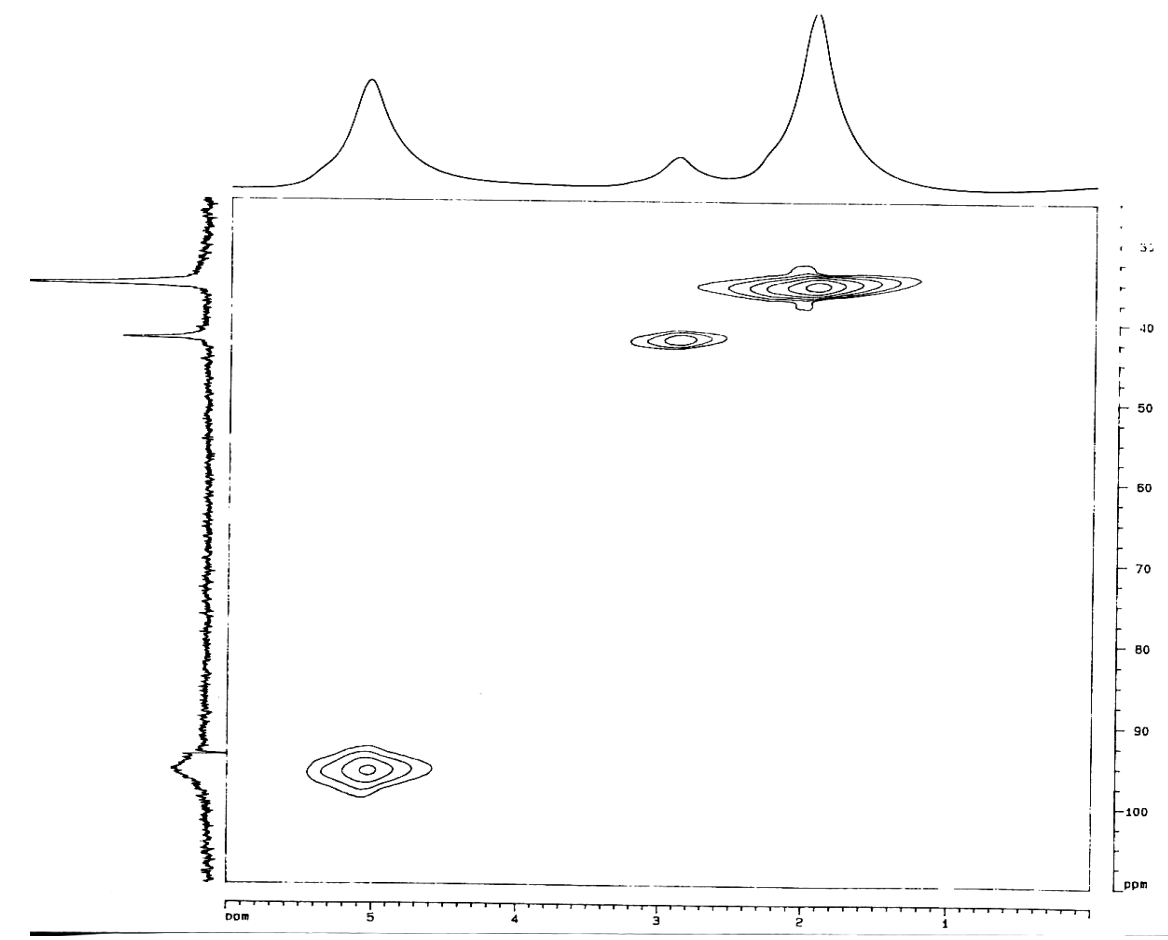

Figure 2. HMQC spectrum of the 2-norbornyl cation correlating ${ }^{1} \mathrm{H}$ and ${ }^{13} \mathrm{C}$ peaks at $-80{ }^{\circ} \mathrm{C}$.

In Figure 3 is shown an EXSY spectrum of the ion at $-80^{\circ} \mathrm{C}$. What is most apparent from this spectrum is that there is now a cross peak between the signal due to $\mathrm{H}-4$ and that due to hydrogen atoms at carbons 1,2 , and 6 . This is due to the fact that the 3,2-hydride shift is occurring and this cross peak shows which hydrogen atoms interchange with other hydrogen atoms in the ion via the 3,2-hydride shift. There is also a cross peak connecting the hydrogen atoms at positions 3, 5, and 7 with those at positions 1, 2, and 6. Similar EXSY spectra were also taken at $-65^{\circ} \mathrm{C}$ and $-50^{\circ} \mathrm{C}$. 


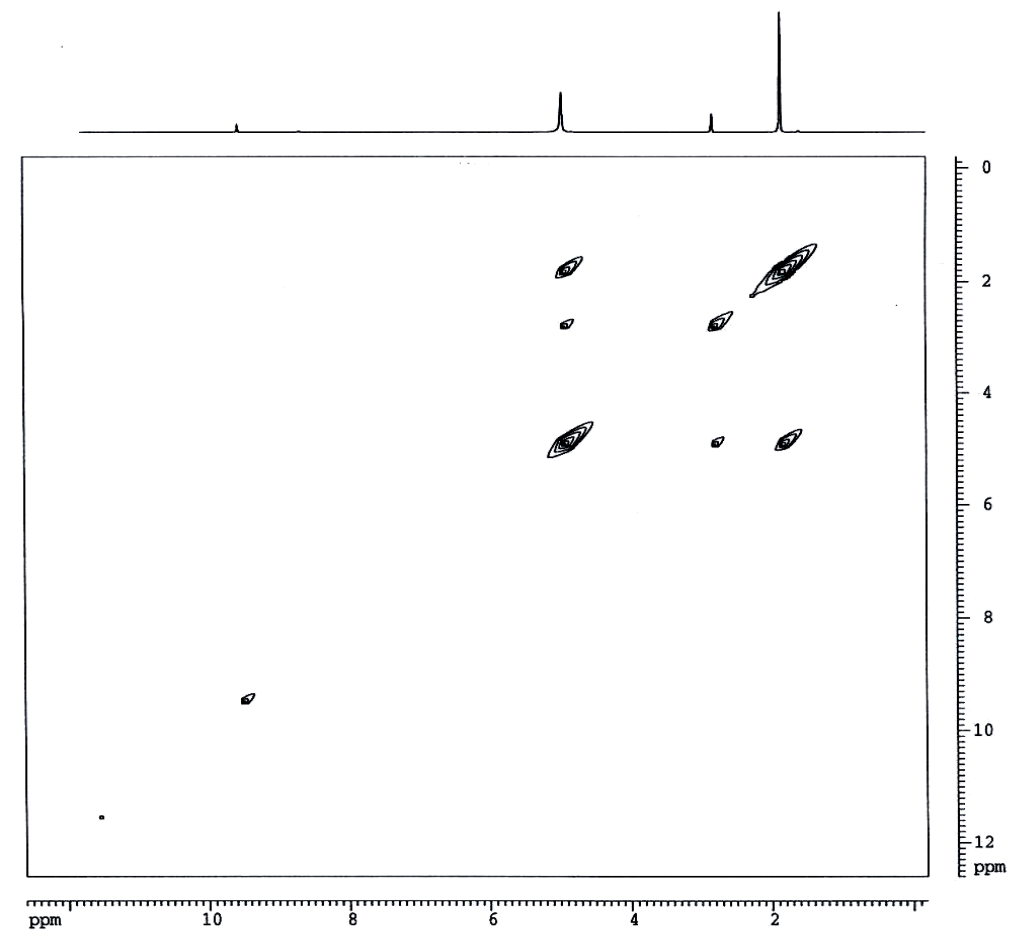

Figure 3. EXSY spectrum of the 2-borbornyl cation at $193 \mathrm{~K}$.

To show how quantitative two-dimensional EXSY can be used to deduce the rates of the 3,2hydride shift a little background material will be given. Our method follows procedures described in Perrin's and Dwyer's review article. ${ }^{5}$ In order to determine accurate rate constants from the EXSY spectra, the exchange rate constants were first estimated from the kinetic data Olah and his students obtained by line shape analysis at higher temperatures. ${ }^{4}$ The relaxation times $\left(T_{1} s\right)$ of the exchanging hydrogen atoms were then determined using the standard inversion-recovery method. ${ }^{6}$ From these data the optical mixing times (opt's) at the three temperatures at which the EXSY spectra were recorded were calculated using the equation:

$$
o p t \approx 1 /\left(T_{1}^{-1}+k_{A B}+k_{B A}\right)
$$

where $\mathrm{k}_{\mathrm{AB}}$ and $\mathrm{k}_{\mathrm{BA}}$ are the estimated rate constants of the 3,2-hydride shift from the Olah data; $\mathrm{k}_{\mathrm{AB}}$ and $\mathrm{k}_{\mathrm{BA}}$ are of course identical in this case. The quantitative two-dimensional EXSY spectra were then obtained at the three temperatures mentioned earlier. The quantitative data were analyzed using equations 2 and 3 , where opt is the optimal mixing time, $X_{A}$ and $X_{B}$ are the mole fractions of the species undergoing exchange, $\mathrm{k}^{\prime}$ is the sum of the forward and reverse reaction rates, $\mathrm{I}_{\mathrm{AA}}$ and $\mathrm{I}_{\mathrm{BB}}$ are the diagonal cross peak intensities, and $\mathrm{I}_{\mathrm{AB}}$ and $\mathrm{I}_{\mathrm{BA}}$ are the cross peak intensities.

$$
k^{\prime}=(1 / \text { opt }) \ln [(r+1) /(r-1)]
$$




$$
r=\left\{4 X_{A} X_{B}\left(I_{A A}+I_{B B}\right) /\left(I_{A B}+I_{B A}\right)\right\}-\left(X_{A} / X_{B}\right)^{2}
$$

Because the forward and reverse rate constants are equal in this case, the rate of the 3,2-hydride shift is given by equation 4 .

$$
k=k^{\prime} /\left(1+X_{A} / X_{B}\right) \quad(\mathrm{Eq} 4)
$$

$\mathrm{T}_{1}$ values, optimal mixing times, and rate constants are given in Tables 1 and 2 . Because there are two sets of cross peaks in each EXSY spectrum, two rate constants are obtained at each temperature. Table 3 lists our rate constants and those of Olah for comparison. The rate constants are in remarkably good agreement with one another. Eyring analysis of our six data points afforded the activation parameters for the 3,2-hydride shift: $\Delta \mathrm{H}^{\ddagger}=12.7 \pm 0.7 \mathrm{kcal} / \mathrm{mol}$ and $\Delta \mathrm{S}^{*}=6.9 \pm 3.6 \mathrm{cal} / \mathrm{mol}-\mathrm{K}$. We were not able to cool the samples sufficiently so that the rates of the 6,2-hydride shift could be obtained by quantitative two-dimensional EXSY.

Table 1. $T_{1}$ values and mixing times as a function of temperature

\begin{tabular}{cccc}
\hline \multirow{2}{*}{ Resonance/ppm } & \multicolumn{3}{c}{$\mathrm{T}_{1} / \mathrm{sec}$} \\
\cline { 2 - 4 } & $193 \mathrm{~K}$ & $208 \mathrm{~K}$ & $223 \mathrm{~K}$ \\
\hline 4.93 & 0.95 & 1.47 & 2.11 \\
2.82 & 1.06 & 1.52 & 2.10 \\
1.85 & 1.60 & 1.73 & 2.06 \\
Mixing times (sec) & 0.3 & 0.06 & 0.01 \\
\hline
\end{tabular}

Table 2. EXSY rate constants

\begin{tabular}{lccc}
\hline Exchange Sites & \multicolumn{3}{c}{ Rate constants $\left(\mathrm{k}, \mathrm{sec}^{-1}\right)$} \\
\cline { 2 - 4 } & $193 \mathrm{~K}$ & $208 \mathrm{~K}$ & $223 \mathrm{~K}$ \\
\hline $4-1,2,6$ & 0.520 & 5.420 & 45.990 \\
$3,5,7-1,2,6$ & 0.450 & 6.470 & 50.380 \\
Average $\mathrm{k}\left(\mathrm{sec}^{-1}\right)$ & 0.485 & 5.945 & 48.185 \\
\hline
\end{tabular}

Table 3. Comparison of our and Olah's data

\begin{tabular}{lll}
\hline Temp/K & $\mathrm{k}_{\text {EXSY }}\left(\mathrm{sec}^{-1}\right)$ & $\mathrm{k}_{\text {lineshape }}\left(\mathrm{sec}^{-1}\right)^{\mathrm{a}}$ \\
\hline 193 & 0.49 & 1.07 \\
208 & 5.95 & 8.15 \\
223 & 48.19 & 47.56 \\
\hline
\end{tabular}

(a) extrapolated values 
Line shape analysis and quantitative two-dimensional EXSY complement each other, with line shape analysis effective at higher temperatures and EXSY at lower temperatures. Working at lower temperatures has one advantage over line shape analysis: The lower temperature regime insures that the ion under investigation does not decompose. Even the 2-norbornyl cation decomposes at elevated temperature. ${ }^{4}$

\section{Experimental Section}

General Procedures. In a typical experiment $0.25 \mathrm{~g}$ of 2-chloronorbornane was placed into a valved ampoule and attached to the vacuum line. To this was condensed $0.500 \mathrm{~g}$ of $\mathrm{SO}_{2} \mathrm{ClF}_{\text {and }}$ the resulting solution brought back to atmospheric pressure with nitrogen gas and allowed to warm to room temperature. In a similar fashion $1.25 \mathrm{~g}$ of $\mathrm{SbF}_{5}$ was mixed with $2.0 \mathrm{~g}$ of $\mathrm{SO}_{2} \mathrm{ClF}$ and the sample warmed to room temperature. In a glove bag equal amounts of the two solutions were mixed, with care being exercised to keep both solutions below $-50^{\circ} \mathrm{C}$. The resulting solution of the cation was added to an nmr tube with J Young valve and, after being sealed, the sample was kept at $-80^{\circ} \mathrm{C}$ until the nmr spectrometer was ready to receive the sample. Low temperature and two-dimensional nmr spectra were obtained on a Varian INOVA $600 \mathrm{MHz}$ or a Bruker AVANCE $400 \mathrm{MHz}$ spectrometer.

\section{Acknowledgements}

This work was supported by the Environmental Protection Agency.

\section{References}

1. Smith, K.; Conley, N.; Hondrogiannis, G.; Glover, L.; Green, J. F.; Mamantov, A.; Pagni, R. M. J. Org. Chem. 2004, 69, 4843.

2. Hondrogiannis, G. unpublished results.

3. Anderson, C.; McGinnis, M.; Vagle, K.; Edwards, A.; Engle, N.; Sick, R.; Kabalka, G. W.; Pagni, R. M. J. Chem. Res. (S) 2003, 726.

4. Olah, G. A.; White, A. M.; DeMember, J. R.; Commeyras, A.; Lui, C. Y. J. Am. Chem. Soc. 1970, 92, 4627.

5. Perrin, C. L.; Dwyer, T. J. Chem. Rev. 1990, 90, 935.

6. Friebolin, H. Basic One- and Two-Dimensional NMR Spectroscopy, $4^{\text {th }}$ Ed.; Wiley-VCH: Weinheim, 2005. 